\title{
Clothing size recommender on real-time fitting simulation using skeleton tracking and rigging
}

\author{
Arik Kurniawati $^{*}$, Ari Kusumaningsih, Yanuar Aliffio \\ Department of Informatics Engineering, Universitas Trunojoyo Madura \\ Jl. Raya Telang Kamal Bangkalan, Madura, Indonesia 69162
}

Cara sitasi: A. Kurniawati, A. Kusumaningsih, and Y. Aliffio, "Clothing size recommender on real-time fitting simulation using skeleton tracking and rigging," Jurnal Teknologi dan Sistem Komputer, vol. 8, no. 2, pp. 127-132, 2020. doi: 10.14710/jtsiskom.8.2.2020.127-132, [Online]

\begin{abstract}
Virtual fitting room (VFR) is a technology that replaces conventional fitting rooms. The VFR is not only available in shops, malls, and any shopping center but also in online stores, which makes VFR technology more and more developed, primarily to support online garment sales. VFR become a trending research interest since Microsoft has developed a Kinect tracking system. In this paper, we proposed the interactive $3 D$ virtual fitting room using Microsoft's Kinect tracking and the rigging technique from $3 D$ Modeling Blender and to implement the VFR. VFR manages the progress of virtual fitting that forms the three-dimensional simulations and visualization of garments on virtual counterparts of the real prospective buyer (user). Users can view the clothing animation on the various poses that are following the user body movements. The system can evaluate the user's match, guiding them to choose the suitable size of the clothes using Euclidean distance.
\end{abstract}

Keywords - virtual fitting room; recommendation system; Kinect; clothing size; body movements

\section{INTRODUCTION}

Virtual fitting room (VFR) is a new technology that facilitates prospective buyers (users) to try several clothes virtually. In this VFR technology, users do not need to physically place their bodies to choose the size, color, style, and other parameters related to buyer satisfaction [1]. In the last few decades, several studies have been applied to develop a virtual fitting room (VFR) due to the tremendous popularity of virtual reality and augmented reality in the garment industry.

The existence of new technologies such as Kinect, a powerful web camera, and a smartphone makes it possible to learn new systems for trying on clothes without doing it physically at the store [2]. VFR implementation in several existing studies and which have been implemented in official stores not only use 2D but also in 3D to display their virtual clothing [3]-[6].

Examples of the application of 2D / 3D in VFR technology, one of which is implemented by Zugara.

\footnotetext{
${ }^{*}$ Corresponding author (Arik Kurniawati)

Email: arik.kurniawati@trunojoyo.ac.id
}

The use of 2D or 3D technology is not a problem for users, but 3D looks more refreshing and is more fun for users. There is comparable to the development costs incurred higher than 2D development. The experience of enjoying VFR is far more essential to prioritize [7]

VFR technology in the last decade, not only available in stores, malls, and shopping centers, but also online stores. This technology makes users comfortably fitting the clothes in real-time without becoming complicated and having to take off their clothes [8]. Especially for online stores whose clothes are physically not available, It can reduce the risk of returning sales because of unsuitable size. For the seller, this will increase sales in the e-commerce perspective [9].

Kinect is one of the most popular technologies used in implementing VFR. The calibration process is carried out by Microsoft Kinect using a 3D depth sensor and an RGB camera makes this VFR application real-time following human movements using a humanoid model [10], and can also be used as a 3D virtual dressing room system [11]. Using Kinect, the user does not need to use any additional control devices to track users' positions, poses, and gestures [12].

Rigging is the process of positioning a frame obtained from a Kinect camera to a human model. With this rigging technique, virtual clothes can be adaptive to the user's movements [13]. Closely related to VFR technology is to recommend the size of the virtual clothes to be tried, one method for measuring clothing sizes can use the Euclidean distance technique [14].

This research proposes a virtual fitting room by combining the concept of 3D virtual cloth, user motion pose adaptation, and cloth size recommender. Unlike [10], [11] which used 3D and humanoid avatars to make it more natural, this study used no virtual avatars, but the original user's body. This study applied the rigging technique from 3D Blender like [4], [12] to simulate virtual clothes that can follow the movements of the consumer's body. To find out the coordinates of the location of $3 \mathrm{D}$ objects using the Kinect calibration process and finally to recommend clothing size, this system used Euclidean distance like [14].

VFR addresses problems when using traditional fitting rooms in stores or malls, such as queuing to try on clothes, having to take off cloth when trying new ones, and the amount of clothing that can be brought to 
room fittings. It also can overcome the problem of mismatching the size, color, and model of clothes when purchasing online. The hope with this VFR technology, users can try clothes without these problems, and users can also move right / left as if trying on clothes in front of a mirror, but the virtual clothes worn are still attached to the body.

\section{RESEARCH METHODS}

\section{A. Making a 3D object and adding a rigging technique}

The creation of the 3D objects used a 3D blender modeling software to simulate virtual clothes which will later be attached to the body of the user. The results of the 3D modeling of virtual batik clothing shown in Figure 1 . The rigging technique applied to add armature (metarig) to 3D objects. This method recognizes virtual clothing to move according to the movements of users. The addition of rigging techniques to virtual clothes can be seen in Figure 2.

\section{B. Calibration process}

The calibration process was carried out by Microsoft Kinect using a 3D depth sensor and an RGB camera. This calibration process produced tracking 3D objects. This method causes Kinect can detect objects that are within the Kinect range. One of the results of 3D Object Tracking is the skeleton data, as shown in Figure 3. This research used only three points of skeleton data, which were skeleton_shoulder_right, skeleton_shoulder_center, and skeleton_shoulder_left. From these three points, the system was able to put virtual clothes on the user's body.

\section{Clothing size recommendation}

The first step for clothing size recommendation was calculating the distance between skeleton_shoulder_right and skeleton_shoulder_left. Vector distance between the two vectors uses Euclidean distance. The distance implemented the Vector3.Distance function in Unity. The next step was comparing these results with the standards of Indonesian clothing size as the basis of the system to provide clothing size recommendations according to Table 1.

\section{Addition of 3D clothing objects to the prospective buyer body}

The addition of 3D clothing was done when users choose the desired clothing. Virtual 3D clothes will be added to the skeleton_shoulder_center, skeleton_shoulder_right, and skeleton_shoulder_left coordinates of users.

\section{RESULTS AND DISCUSSION}

This experiment was conducted to determine the value of the accuracy of clothing size recommendations given by the system. The accuracy measurement used variations in the distance between users with Kinect sensors and Kinect height, and the influence of poses

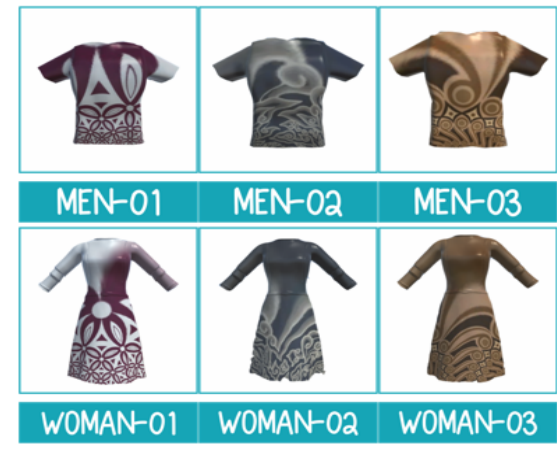

Figure 1. 3D modeling of virtual batik clothing
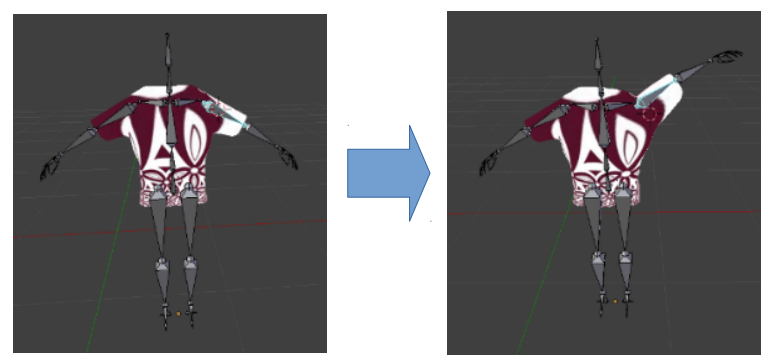

Figure 2. The addition of rigging techniques to virtual clothes

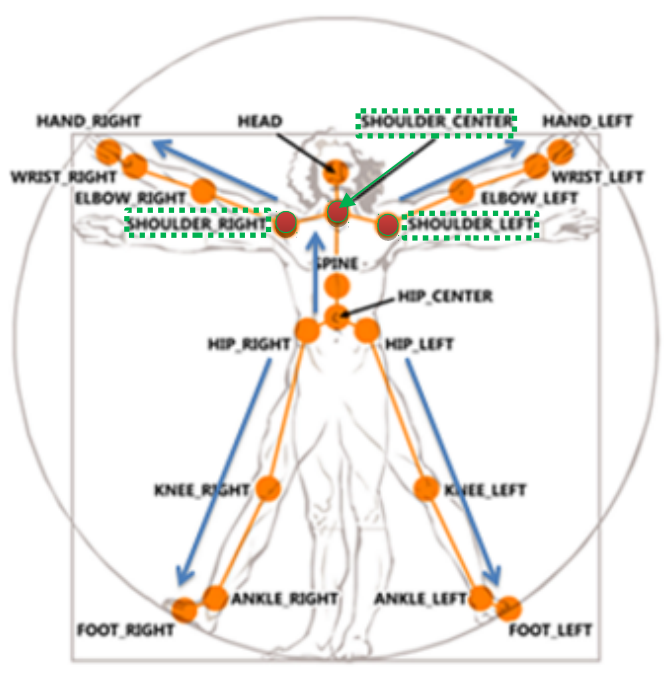

Figure 3. Skeleton data of 3D object tracking by Kinect

Table 1. Standardized adult clothes size

\begin{tabular}{lcccc}
\hline \multirow{2}{*}{ Size } & \multicolumn{4}{c}{ Clothing size } \\
\cline { 2 - 5 } & S & M & L & XL \\
\hline Back width (M) & $40 \mathrm{~cm}$ & $42 \mathrm{~cm}$ & $44 \mathrm{~cm}$ & $46 \mathrm{~cm}$ \\
Back width (F) & $36 \mathrm{~cm}$ & $38 \mathrm{~cm}$ & $40 \mathrm{~cm}$ & $42 \mathrm{~cm}$ \\
\hline
\end{tabular}

made by users on the recommended clothing sizes provided by the system. This experiment was implemented with five conditions. 
Table 2. Experiment result of recommendation of size clothing systems for female

\begin{tabular}{|c|c|c|c|c|c|c|c|c|c|c|}
\hline \multirow{3}{*}{$\begin{array}{c}\text { Object } \\
\text { experiment }\end{array}$} & \multirow{3}{*}{$\begin{array}{l}\text { Clothing } \\
\text { size }\end{array}$} & \multicolumn{9}{|c|}{$\begin{array}{l}\text { Recommendations } \\
\text { Kinect height: } 65 \mathrm{~cm}\end{array}$} \\
\hline & & \multicolumn{9}{|c|}{ Range (in cm) } \\
\hline & & 200 & 225 & 250 & 200 & 225 & 250 & 200 & 225 & 250 \\
\hline Female 1 & $\mathrm{M}$ & $\mathrm{M}$ & $\mathrm{L}$ & $\mathrm{M}$ & $\mathrm{M}$ & $\mathrm{M}$ & $\mathrm{M}$ & $\mathrm{M}$ & $\mathrm{M}$ & $\mathrm{S}$ \\
\hline Female 2 & $\mathrm{~L}$ & $\mathrm{~L}$ & $\mathrm{~L}$ & M & M & M & $\mathrm{M}$ & M & $\mathrm{M}$ & M \\
\hline Female 3 & $\mathrm{~S}$ & S & M & $\mathrm{S}$ & $\mathrm{S}$ & $\mathrm{S}$ & S & S & $\mathrm{S}$ & S \\
\hline Female 4 & $\mathrm{~L}$ & $\mathrm{~L}$ & M & $\mathrm{L}$ & $\mathrm{L}$ & M & S & M & S & S \\
\hline Female 5 & S & S & $\mathrm{S}$ & S & S & $\mathrm{S}$ & S & S & S & S \\
\hline Female 6 & $\mathrm{~S}$ & S & M & S & S & $\mathrm{L}$ & $\mathrm{M}$ & M & $\mathrm{S}$ & M \\
\hline Female 7 & $\mathrm{~L}$ & $\mathrm{~L}$ & $\mathrm{~L}$ & $\mathrm{~L}$ & XL & $\mathrm{L}$ & $\mathrm{M}$ & $\mathrm{L}$ & $\mathrm{L}$ & $\mathrm{L}$ \\
\hline Female 8 & $\mathrm{~L}$ & $\mathrm{~L}$ & M & M & $\mathrm{L}$ & $\mathrm{L}$ & $\mathrm{M}$ & $\mathrm{L}$ & $\mathrm{L}$ & $\mathrm{L}$ \\
\hline Female 9 & $\mathrm{~L}$ & $\mathrm{~L}$ & M & M & $\mathrm{L}$ & M & $\mathrm{M}$ & M & $\mathrm{L}$ & M \\
\hline Female 10 & M & M & $\mathrm{M}$ & M & M & $S$ & S & M & $S$ & M \\
\hline Female11 & M & M & M & M & M & M & $\mathrm{M}$ & M & $\mathrm{M}$ & M \\
\hline Female 12 & M & M & $\mathrm{M}$ & $\mathrm{L}$ & M & M & $\mathrm{M}$ & M & $\mathrm{L}$ & M \\
\hline Female 13 & $\mathrm{~L}$ & $\mathrm{~L}$ & M & $\mathrm{L}$ & M & $\mathrm{L}$ & M & $\mathrm{L}$ & M & $\mathrm{L}$ \\
\hline
\end{tabular}

Table 3. Experiment result of recommendation of size clothing systems for male

\begin{tabular}{|c|c|c|c|c|c|c|c|c|c|c|}
\hline \multirow{3}{*}{$\begin{array}{c}\text { Object } \\
\text { experiment }\end{array}$} & \multirow{3}{*}{$\begin{array}{l}\text { Clothing } \\
\text { size }\end{array}$} & \multicolumn{8}{|c|}{ Recommendations } & Kinect height: $75 \mathrm{~cm}$ \\
\hline & & & & & \multicolumn{3}{|c|}{$\begin{array}{c}\text { Kinect height: } 65 \mathrm{~cm} \\
\text { Range (in } \mathrm{cm})\end{array}$} & & & \\
\hline & & 200 & 225 & 250 & 200 & 225 & 250 & 200 & 225 & 250 \\
\hline Male 1 & $\mathrm{~L}$ & $\mathrm{~L}$ & $\mathrm{~L}$ & $\mathrm{XL}$ & $\mathrm{L}$ & $\mathrm{L}$ & $\mathrm{L}$ & $\mathrm{L}$ & $\mathrm{XL}$ & $\mathrm{L}$ \\
\hline Male 2 & XL & XL & XL & XL & XL & XL & XL & XL & XL & XL \\
\hline Male 3 & M & $\mathrm{M}$ & $\mathrm{M}$ & $\mathrm{M}$ & $\mathrm{M}$ & $\mathrm{M}$ & $\mathrm{M}$ & $\mathrm{M}$ & $\mathrm{M}$ & $\mathrm{M}$ \\
\hline Male 4 & M & $\mathrm{M}$ & $\mathrm{M}$ & $\mathrm{M}$ & $\mathrm{M}$ & M & M & M & M & M \\
\hline Male 5 & $\mathrm{~L}$ & $\mathrm{M}$ & $\mathrm{S}$ & $\mathrm{M}$ & $\mathrm{M}$ & $\mathrm{L}$ & M & $\mathrm{L}$ & $\mathrm{L}$ & M \\
\hline Male 6 & $\mathrm{~L}$ & $\mathrm{~L}$ & $\mathrm{~L}$ & $\mathrm{~L}$ & $\mathrm{~L}$ & $\mathrm{~L}$ & $\mathrm{~L}$ & $\mathrm{~L}$ & $\mathrm{~L}$ & $\mathrm{~L}$ \\
\hline Male 7 & XL & $\mathrm{L}$ & XL & XL & XL & XL & XL & XL & XL & XL \\
\hline Male 8 & M & $\mathrm{M}$ & $\mathrm{M}$ & $\mathrm{M}$ & $\mathrm{M}$ & $\mathrm{L}$ & $\mathrm{M}$ & $\mathrm{M}$ & $\mathrm{L}$ & $\mathrm{M}$ \\
\hline Male 9 & M & $\mathrm{S}$ & $\mathrm{M}$ & $\mathrm{M}$ & $\mathrm{M}$ & $\mathrm{L}$ & $\mathrm{L}$ & $\mathrm{M}$ & M & $\mathrm{S}$ \\
\hline Male 10 & $\mathrm{~L}$ & $\mathrm{M}$ & $\mathrm{M}$ & $\mathrm{M}$ & $\mathrm{L}$ & $\mathrm{L}$ & $\mathrm{L}$ & $\mathrm{L}$ & $\mathrm{L}$ & $\mathrm{L}$ \\
\hline
\end{tabular}

\section{A. Clothing size recommendations with variations in distance and height from Kinect}

In this step, analysis and experiment were carried out to determine the level of system accuracy. The analysis variables used are Kinect height (Kinect placement distance measured from the flat ground) and the distance between users and Kinect sensors. Kinect height is expressed into three measures, namely $55 \mathrm{~cm}$, $65 \mathrm{~cm}$, and $75 \mathrm{~cm}$. The distance of users with Kinect sensors is distinguished by a distance of $200 \mathrm{~cm}, 225$ $\mathrm{cm}$, and $250 \mathrm{~cm}$.

This experiment was tested directly on 23 users consisting of 13 women and 10 men who were randomly selected. A total of 117 trials were conducted for women's clothing and 90 trials for men's clothing. Details of the analysis results can be seen in Table 2 and Table 3, while Table 4 shows the recapitulation results summarized from both tables.

It can be concluded that the Euclidean distance method can be used to measure the user's back distance. The Euclidean distance between skeleton_shoulder_right and skeleton_shoulder_left can be used as the basis for determining the recommended clothing size as [14]. The average accuracy rate of this system is $81 \%$ for males and $69 \%$ for females, as shown in Table 4.

The best accuracy for this scenario is achieved with a Kinect placement height of $55 \mathrm{~cm}$ for female users and of $75 \mathrm{~cm}$ for male users with a distance of $200 \mathrm{~cm}$ between the user and Kinect. This corresponds to [8] which recommends that the optimal placement point for Kinect height be $55 \mathrm{~cm}$ and $75 \mathrm{~cm}$ with the distance between the user and Kinect is $200 \mathrm{~cm}$.

\section{B. Simulation of virtual clothes in real-time according to the motion of users}

This analysis and experiment were carried out to arrange the position of $3 \mathrm{D}$ virtual clothes to match the user's body position and to simulate the movement of virtual clothes following body movements in real-time. Figure 4 shows clothes attached to the body of a user, while Figure 5 is a real-time simulation of virtual clothes following the user's body movements. These results are in accordance with the previous studies in [4], [13]. 
Table 4. Recapitulation of the level of accuracy for recommendations on clothing size

\begin{tabular}{|c|c|c|c|c|c|}
\hline \multirow{3}{*}{ Height of kinect } & \multirow{3}{*}{$\begin{array}{c}\text { Range of } \\
\text { kinect }\end{array}$} & \multicolumn{4}{|c|}{ Recommendations } \\
\hline & & \multicolumn{2}{|c|}{ Male } & \multicolumn{2}{|c|}{ Female } \\
\hline & & True & False & True & False \\
\hline \multirow[t]{4}{*}{$55 \mathrm{~cm}$} & $200 \mathrm{~cm}$ & 6 & 4 & 13 & 0 \\
\hline & $225 \mathrm{~cm}$ & 9 & 1 & 5 & 8 \\
\hline & $250 \mathrm{~cm}$ & 7 & 3 & 10 & 3 \\
\hline & Accuracy & & & & \\
\hline \multirow[t]{4}{*}{$65 \mathrm{~cm}$} & $200 \mathrm{~cm}$ & 9 & 1 & 10 & 3 \\
\hline & $225 \mathrm{~cm}$ & 8 & 2 & 9 & 4 \\
\hline & $250 \mathrm{~cm}$ & 8 & 2 & 7 & 6 \\
\hline & Accuracy & & & & \\
\hline \multirow[t]{5}{*}{$75 \mathrm{~cm}$} & $200 \mathrm{~cm}$ & 10 & 0 & 9 & 4 \\
\hline & $225 \mathrm{~cm}$ & 8 & 2 & 9 & 4 \\
\hline & $250 \mathrm{~cm}$ & 8 & 2 & 9 & 4 \\
\hline & Accuracy & & & & \\
\hline & Average & & & & \\
\hline
\end{tabular}

\section{Clothing size recommendations with user's poses variation}

Table 5 shows the result of an analysis and experiment conducted to determine the influence of users' poses on system size recommendations. Five poses are done; there are stand up straight (1), stretching hands (2), hands forward (3), stand oblique to the right (4), and stand oblique to the left (5).

Various poses cause Kinect calibration reference points (skeleton_shoulder_right and skeleton_shoulder_left) are also different, thus also affecting recommended clothing size recommendations. The best pose for recommended clothing size is the first pose (stand up straight). The virtual clothes can adapt to the user's movements according to [4], although the results of the recommendation of clothing sizes with different poses make the recommended size unstable.

\section{The effects of users moving forward and backward from Kinect}

This analysis and testing were conducted to determine the effect of Kinect distance on the performance of this virtual clothing. In general, the image will look smaller if it is far from the mirror view and vice versa. This experiment shows how virtual clothes are simulated when the user is at a distance of $200 \mathrm{~cm}, 225 \mathrm{~cm}$, and $250 \mathrm{~cm}$. The results of this experiment can be seen in Figure 6, where when the user stays away from Kinect, virtual clothes become smaller. From Table 5, it can be concluded that the

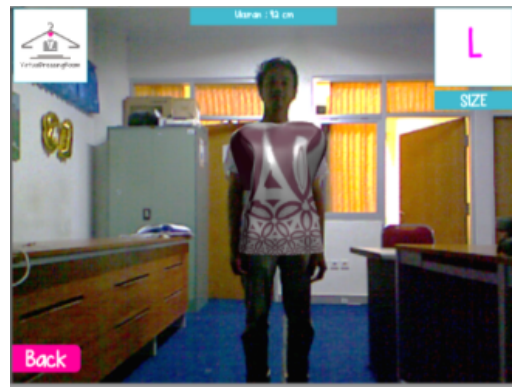

Figure 4. Virtual clothes attached to the user's body



Figure 5. The virtual dress can adapt to the user pose (male and female)

Kinect distance slightly affects the clothing size recommendations for the best pose 1 .

\section{E. Accuracy based on user height}

This analysis and experiment were conducted to discover the effect of the user's height in determining clothing size recommendations. This experiment was

Table 5. Experiment result of recommendation of size clothing systems for pose variations

\begin{tabular}{|c|c|c|c|c|c|c|c|c|c|c|c|c|c|c|c|c|}
\hline \multirow{3}{*}{$\begin{array}{c}\text { Object } \\
\text { experiment }\end{array}$} & \multirow{3}{*}{$\begin{array}{c}\text { Clothing } \\
\text { size }\end{array}$} & \multicolumn{15}{|c|}{ Recommendations (Kinect height: $75 \mathrm{~cm}$ ) } \\
\hline & & \multicolumn{5}{|c|}{ Range: $200 \mathrm{~cm}$} & \multicolumn{5}{|c|}{ Range: $225 \mathrm{~cm}$} & \multicolumn{5}{|c|}{ Range: $250 \mathrm{~cm}$} \\
\hline & & 1 & 2 & 3 & 4 & 5 & 1 & 2 & 3 & 4 & 5 & 1 & 2 & 3 & 4 & 5 \\
\hline Male 1 & $\mathrm{~L}$ & $\mathrm{~L}$ & $\mathrm{XL}$ & $\mathrm{L}$ & $\mathrm{L}$ & $\mathrm{L}$ & $\mathrm{L}$ & $\mathrm{XL}$ & $\mathrm{L}$ & $\mathrm{L}$ & $\mathrm{L}$ & $\mathrm{L}$ & XL & $\mathrm{L}$ & $\mathrm{L}$ & $\mathrm{L}$ \\
\hline Male 2 & $\mathrm{~L}$ & $\mathrm{~L}$ & XL & M & $\mathrm{L}$ & $\mathrm{XL}$ & $\mathrm{L}$ & XL & M & XL & XL & XL & XL & $\mathrm{M}$ & XL & XL \\
\hline Female 1 & $\mathrm{~L}$ & $\mathrm{~L}$ & XL & M & M & M & $\mathrm{L}$ & XL & M & M & $\mathrm{M}$ & $\mathrm{L}$ & XL & M & M & M \\
\hline Female 2 & $\mathrm{M}$ & $\mathrm{M}$ & $\mathrm{M}$ & $\mathrm{S}$ & $\mathrm{S}$ & $\mathrm{S}$ & $\mathrm{M}$ & M & $\mathrm{S}$ & $\mathrm{M}$ & $\mathrm{M}$ & $\mathrm{M}$ & $\mathrm{M}$ & $\mathrm{S}$ & $\mathrm{M}$ & $\mathrm{M}$ \\
\hline
\end{tabular}




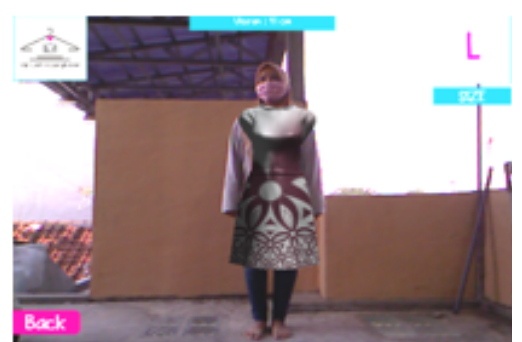

(a)



(b)

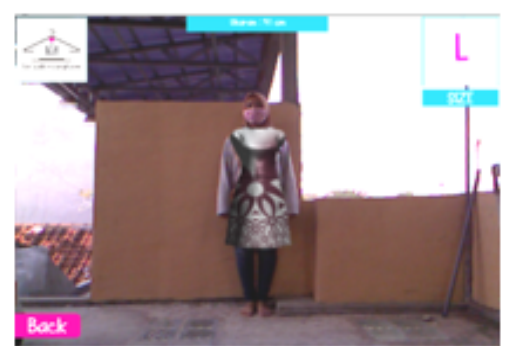

(c)

Figure 6. Scaling of virtual 3D clothes (the distance between the user and kinect are $200 \mathrm{~cm}$ (a), $225 \mathrm{~cm}$ (b) and 250 $\mathrm{cm}(\mathrm{c}))$

Table 6. The experiment result of the recommendation of size clothing systems for various user's height

\begin{tabular}{|c|c|c|c|c|c|c|c|c|c|c|}
\hline \multirow{3}{*}{$\begin{array}{c}\text { Object } \\
\text { experiment }\end{array}$} & \multirow{3}{*}{$\begin{array}{l}\text { Clothing } \\
\text { size }\end{array}$} & \multicolumn{8}{|c|}{ Recommendations } & $5 \mathrm{~cm}$ \\
\hline & & & & & \multicolumn{3}{|c|}{$\begin{array}{c}\text { Kinect height: } 65 \mathrm{~cm} \\
\text { Range (in } \mathrm{cm} \text { ) }\end{array}$} & & & \\
\hline & & 200 & 225 & 250 & 200 & 225 & 250 & 200 & 225 & 250 \\
\hline Male $3(176 \mathrm{~cm}$ & $\mathrm{M}$ & $\mathrm{M}$ & $\mathrm{M}$ & $\mathrm{M}$ & $\mathrm{M}$ & $\mathrm{M}$ & $\mathrm{M}$ & $\mathrm{M}$ & $\mathrm{M}$ & $\mathrm{M}$ \\
\hline Male $4(162 \mathrm{~cm})$ & M & M & $\mathrm{M}$ & $\mathrm{M}$ & $\mathrm{M}$ & M & $\mathrm{M}$ & M & $\mathrm{M}$ & M \\
\hline
\end{tabular}

carried out by taking two samples, one man who had the highest height and one man who had the shortest height of all users.

From Table 6, it can be concluded that the height of the user does not affect the clothing size recommendations. The height of the user does not affect the recommended clothing size as long as the whole body of the user is in the Kinect coverage area.

From all of these experiments, making 3D clothing objects with rigging in the form of adding armature to 3D clothing objects can make virtual clothing adaptable to the movements of users in real-time. When users raise their hands, the arms on the clothes also lift. Virtual clothing simulations can follow the motion of users and always stick precisely to the user body. The Euclidean distance method in this system can provide clothing size recommendations to users with an average accuracy rate of $81 \%$ for male and $69 \%$ for female using a variety of Kinect heights $(55 \mathrm{~cm}, 65 \mathrm{~cm}$, and 75 $\mathrm{cm})$ and variations in the Kinect distance with users ranging from $200 \mathrm{~cm}, 225 \mathrm{~cm}$ and $250 \mathrm{~cm}$. The recommended size of clothes is influenced by the height of the Kinect, the distance between the user and the Kinect, the pose of the user. The user's height does not affect the outcome of clothing size recommendations.

The VFR technology proposed in this paper can simulate the movement of clothing following the user's body pose almost the same as previous studies using Kinect in [4], [12] and not replacing people with avatars [2], [13]. However, this research is limited to virtual clothing without accessories other supporters, unlike previous studies that use various types of complementary accessories [5]. This study also produced recommendations about clothing sizes using the same techniques as in [14], but not as detailed as measuring clothing size patterns as revealed in [6].

\section{CONCLUSION}

The proposed virtual fitting room can simulate the user's motion with rigging technology in Blender 3D modeling with the addition of metarig. The virtual clothing can follow the user's movements (such as the user raises his hands up, then the arms of the clothes also lift up). The calibration process provided by Microsoft Kinect makes virtual clothes exactly on the user's body. The clothing size recommendations generated by the system using the Euclidian distance method has an average accuracy rate of $81 \%$ for male and $69 \%$ for female. The height of the Kinect influences the results of these recommendations, the distance between the Kinect and the user, and the user's pose, while the height of the user does not affect the results of the clothing size recommendation.

\section{REFERENCES}

[1] N. Y. Albany, "Virtual fitting room market influential factors determining the trajectory of the market,” Transparency Market Research, SBWIRE, 2017. [online]. Available: http://www.sbwire.com/ press-releases/virtual-fitting-room-market/release779312.htm

[2] C. A. B. Rodriquez, "Virtual fitting room,” Master thesis, Universidad Politecnica De Madrid, Spain, 2016

[3] V. Kulkarni, S. Morde, B. Pawar, S. Mahadik, and R. Dahore, "2D virtual trial room using augmented reality,” International Journal on Future Revolution in Computer Science \& Communication Engineering, vol. 4, no. 1, pp. 226-228, 2018.

[4] J. P. Bansidhar, B. S. Hiraman, M. K. Tanaji, S. V. More, and B. S. Shirole, "A virtual dressing room using Kinect,” International Journal of Scientific 
Research in Science and Technology, vol. 3, no. 3, pp. 384-389, 2017.

[5] I. Pachoulakis and K. Kapetanakis, "Augmented reality platforms for virtual fitting rooms," The International Journal of Multimedia \& Its Applications (IJMA), vol. 4, no. 4, pp. 35-46, 2012. doi: 10.5121/ijma.2012.4404

[6] C. Cheng, D. S. Liu, C. Tsai, and L. Chen, "A 3D virtual show room for online apparel retail shop," in 2009 APSIPA Annual Summit and Conference, Sapporo, Japan, Oct. 2009, pp. 193-199.

[7] M. Szymczyk, "When to use 2D vs. 3D virtual dressing room technology,” Zugara, 2019. [online]. Available: http://zugara.com/when-to-use2d-vs-3d-virtual-dressing-room-technology

[8] A. Kusumaningsih, A. Kurniawati, C.V. Angkoso, E.M. Yuniarno, and M. Hariadi, "User experience measurement on virtual dressing room of Madura batik clothes," in International Conference on Sustainable Information Engineering and Technology, Malang, Indonesia, Nov. 2017, pp. 203-208. doi: 10.1109/SIET.2017.8304135

[9] F. Pereira, C. Silva, and M. Alves, "Virtual fitting room augmented reality techniques for ecommerce," in International Conference on ENTERprise Information Systems, Vilamoura,
Portugal, Oct. 2011, pp. 62-71. doi: 10.1007/9783-642-24355-4_7

[10] M. Kotan and C. Öz, "Virtual dressing room application with virtual human using Kinect sensor," Journal of Mechanics Engineering and Automation, vol. 5, pp 322-326, 2015. doi: 10.17265/2159-5275/2015.05.008

[11] K. W. Mok, C. T. Wong, S. K. Choi, and L. M. Zhang, "Design and development of virtual dressing room system based on Kinect," International Journal Information Technology and Computer Science, vol. 9, pp. 39-46, 2018. doi: 10.5815/ijitcs.2018.09.05

[12] L. Ziquan, “Augmented reality: virtual fitting room using Kinect,” B. Comp. Dissertation, National University of Singapore, Singapore, 2012.

[13] A. Shingade and A. Ghotkar, "Animation of 3D human model using markerless motion capture applied to sports,” International Journal of Computer Graphics \& Animation (IJCGA), vol. 4, no. 1, pp. 27-39, 2014. doi: 10.5121/ijcga.2014.4103

[14] R. Rizaldi, A. Kurniawati, and C. V. Angkoso, "Implementasi metode Euclidean distance untuk rekomendasi ukuran pakaian pada aplikasi ruang ganti virtual,” Jurnal Teknologi Informasi dan Ilmu Komputer, vol. 5, no. 2, pp. 129-138, 2018. doi: 10.25126/jtiik.201852592 